\title{
Una nueva especie del Género Opuntia (CACTACEAe) para el estado de Veracruz, México
}

\author{
Léla Scheinvar ${ }^{1,3}$, Gabrel Olalde-Parra ${ }^{1}$ y Clemente Gallegos-Vázquez ${ }^{2}$ \\ 'Jardín Botánico, Instituto de Biología, Universidad Nacional Autónoma de México, México, D.F., México \\ ${ }^{2}$ Centro Regional Universitario Centro-Norte de la Universidad Autónoma Chapingo, Zacatecas, México \\ ${ }^{3}$ Autor para la correspondencia: leiascheinvar@gmail.com
}

\begin{abstract}
Resumen: Se describe e ilustra la Opuntia perotensis Scheinvar, Olalde \& Gallegos, nueva especie de un nopal silvestre del Frijol Colorado, Cofre de Perote, Veracruz, México. La nueva especie estaba identificada como O. huajuapensis Bravo en el herbario del Instituto de Investigaciones Biológicas de la Universidad Veracruzana. Opuntia huajuapensis es una especie endémica de la mixteca oaxacense, distinguiéndose de $O$. perotensis, la cual presenta epidermis papilosa, cladodios con espinas en todas las aréolas, con algunos pelos negros; flores de dos colores; frutos subglobosos con paredes anchas; arilo piloso, semillas ubicadas en el centro del fruto y granos de polen de dos tipos morfológicos. Se considera que se trata de una especie nueva, posiblemente de origen híbrida, ubicada en la serie Criniferae Pfeiff.
\end{abstract}

Palabras clave: Cofre de Perote, nopal, Opuntia huajuapensis, serie Criniferae.

\begin{abstract}
Opuntia perotensis Scheinvar Olalde \& Gallegos, a new cactus pear species from Frijol Colorado, Cofre de Perote, Veracruz, Mexico, is described and illustrated. The new species was identified as Opuntia huajuapensis Bravo in the herbarium of the Instituto de Investigaciones Biológicas of the Universidad Veracruzana. Opuntia huajuapensis is an endemic species from "mixteca oaxacense"; differing of $O$. perotensis that has a papillose skin; cladodes with spines in all areoles, with few black hairs, two colors of flowers; subglobose fruits with thick walls; aril hairy, seeds located in the center of the fruit and pollen grains with two morphologic types. It belongs to the series Criniferae Pfeiff.
\end{abstract}

Key words: cactus-pear, Criniferae series, Opuntia huajuapensis, Perote.

$\mathbf{E}^{1}$ género Opuntia pertenece a la subfamilia Opuntioideae. Se caracteriza por presentar cladodios encadenados, verdes, en forma de raqueta y aréolas con glóquidas (ahuates, en náhuatl), que son espinas reducidas, hojas subuladas reducidas y deciduas, solo presentes en cladodios juveniles; todas las estructuras están adaptadas para la absorción y retención de agua. México es un centro de diversificación de este género, se encuentran 103 especies silvestres (Scheinvar et al., en prensa). Los nopales tienen un importante potencial por sus usos múltiples: ecológico, alimenticio (frutícola y nopal-verdura), medicinal, histórico-cultural, económico, forrajero, para la recuperación de tierras degradadas y reforestación de zonas áridas y semiáridas (Bravo-Hollis y Scheinvar, 1995; Felker, 2001; González et al., 2001). La gran diversidad genética a nivel inter e intra específico de los nopales, que se refleja en sus características fenológicas, se debe a que los nopales silvestres florecen casi todos al mismo tiempo y no hay barreras que impidan su hibridación, así como el retro-cruzamiento, que ocurre con frecuencia. Por otro lado, hay gran número de poliploides, lo que contribuye a la gran variabilidad morfológica, a la existencia de tan numerosas especies distintas y a la variación dentro de cada población de la misma especie. El género Opuntia está representado por gran número de híbridos y de poliploides, por lo que Pinkava et al. (1985) han sugerido tratarlo como un género complejo. Pinkava (2002), en su artículo sobre el origen y la evolución de las Opuntioideae de Norteamérica, anota varios factores que favorecen la especiación rápida y exitosa de los nopales, y que son: (1) poblaciones pequeñas, aisladas vía especiación peripátrica que permite la fijación de nuevas combinaciones genéticas y la invasión de nuevos hábitats; (2) reproducción sexual, que provee de nuevas recombinaciones genéticas que pueden favorecer su adaptación y éxito en la selección natural; (3) hábito peren- 
ne, lo que permite más tiempo para que se adapten y fijen las recombinaciones genéticas y mutaciones; (4) apomixis, autofecundación de flores antes de que las anteras maduren, habiendo aislamiento de sus polinizadores, sin que ocurra la fecundación cruzada; el producto es haploide y las semillas se atrofian; (5) poliploidía, un individuo que presenta 3 n o más cromosomas, lo que provee ADN adicional, del cual nuevos genes y combinaciones podrían producirse sin interrupción de la estructura normal y de los procesos fisiológicos; (6) hibridación intraespecífica que provee un incremento en la variabilidad debido al potencial de los nuevos genes que interactúan; comúnmente observada porque hay pocas barreras de cruzamiento entre la mayoría de las especies que florecen al mismo tiempo. La hibridación generalmente va acompañada de poliploidia, particularmente en los nuevos híbridos o nuevos hábitats; las especies así originadas son más resistentes y más agresivas que las diploides, y muchas veces son invasoras de terrenos fértiles. Se puede agregar:
(7) reproducción vegetativa o clonal, por enraizamiento, a partir de aréolas de los cladodios, de los pericarpelos de las flores o de los frutos inmaduros caídos al suelo, originando plantas con características idénticas a la planta de la cual se desprendieron (Scheinvar et al., en prensa).

En la presente investigación se describe e ilustra una nueva especie del género Opuntia, que se distribuye en el Frijol Colorado, Cofre de Perote, Veracruz, incluyendo características macromorfológicas de los órganos vegetativos y reproductivos y, micromorfológicas, vistas con el microscopio electrónico de barrido, de glóquidas, espinas, granos de polen y semillas.

Opuntia perotensis Scheinvar, Olalde \& Gallegos, sp. nov. (Figuras 1-4).

Subshrubby or creeping habit. Trunk absent. Epidermis powdery, shiny, with papillose skin. Stomata cyclocytic. Areoles in 11-12 series, distant 0.8-1.5 cm apart, with blac-
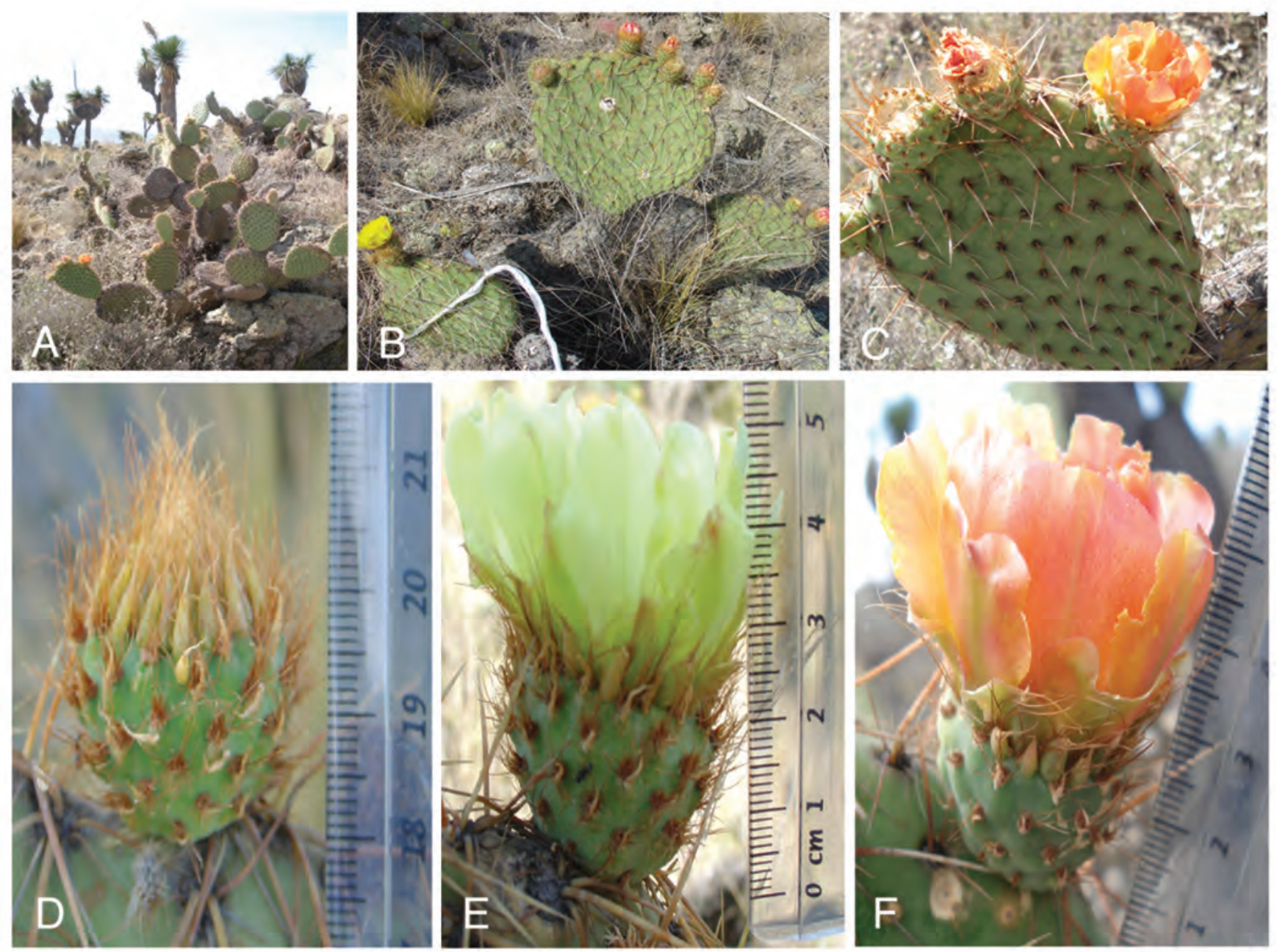

Figura 1. Opuntia perotensis sp. nov. A) Hábito. Planta subarbustiva y rastrera, sin tronco en matorral xerófilo con Nolina sp. B) Cladodios anchamente obovados a subcirculares, con espinas largas que lo recubren, botones florales y flor amarilla, vista exterior. C) Cladodio obovado, con espinas, flores amarillo-rosadas y fruto verde. D) Botón floral. E) Flor blanco-verdosa. Vista exterior. F) Flor amarillo-rosada, pericarpelo similar en ambas flores. 

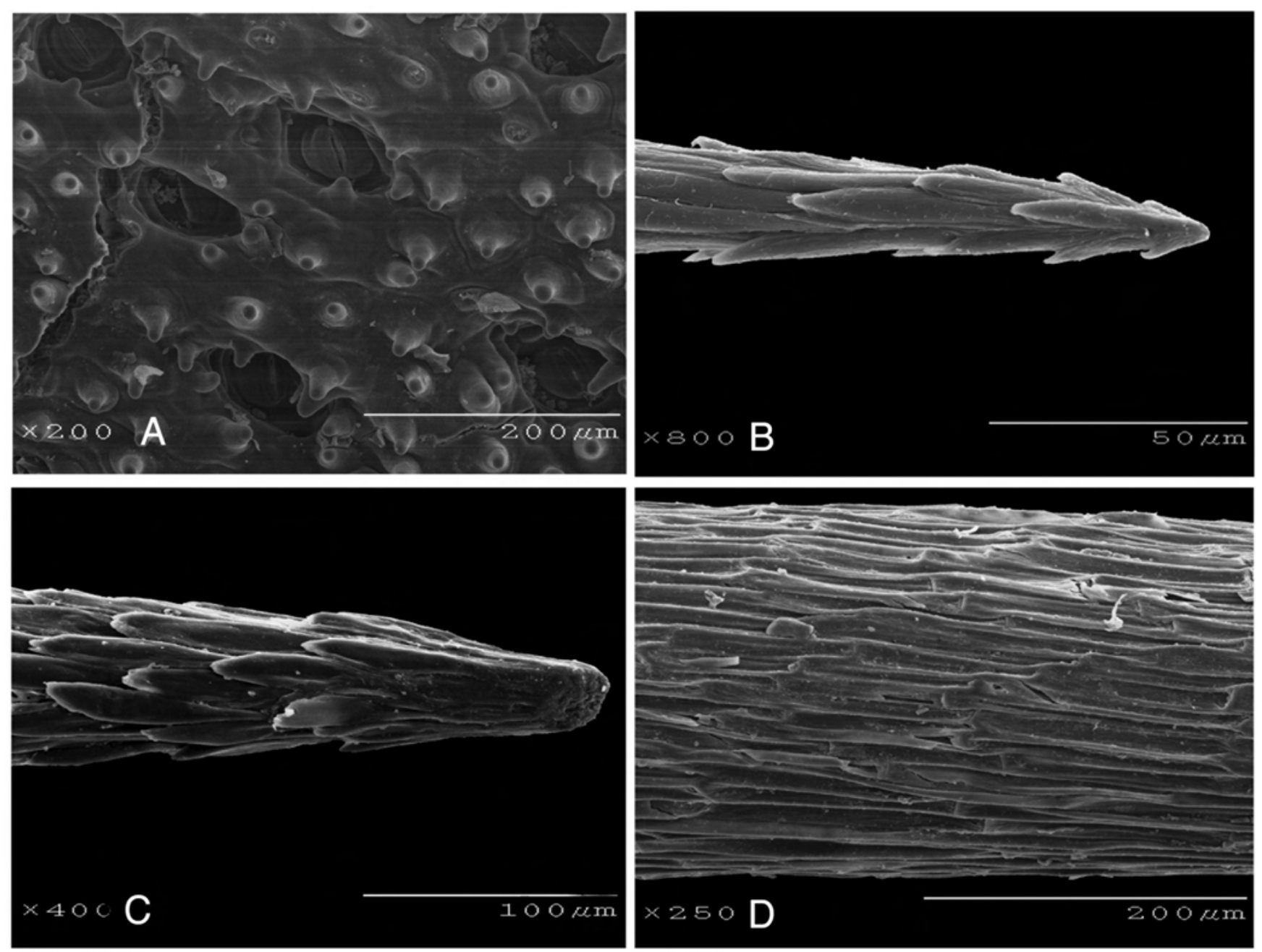

Figura 2. Opuntia perotensis sp. nov. A) epidermis papilosa, B) glóquida, parte apical, C) ápice de una espina, D) parte media de la espina.

kish-brown felt. Bristles 1-5, wavy, yellow-gray and brown. Glochids SEM views with high, numerous and long retrorse beards. Spines with reddish or brown point with long and somewhat elevated scales. Median region with 26 parallel cells, without intercellular spaces. Yellowish-brown bristles. Flowers at anthesis, yellow and/or pink. Areoles of pericarpel with few bristling spines $<1 \mathrm{~cm}$. Outer segments with green apex. Filaments pale yellow to pink. Stigma lobes 1012, pink. Pollen grains of two types: one with 12 pores and open foramina, and other with 20 pores and foramina very closed. Fruits $4-5 \mathrm{~cm}$. Seeds reniform, in the center of the fruit, covered with long, scattered trichomes.

TIPO: México. Veracruz, Municipio Perote, Cofre de Perote, $1.5 \mathrm{~km}$ al SO del Poblado Frijol Colorado, Lat. N 19³4' 44.6”, Long. O $97^{\circ} 21^{\prime}$ 50.8”, matorral xerófilo, suelo arcilloso, café claro, sobre derrame basáltico, 2,430 m s.n.m., 16 de junio de 2011. Gustavo Moreno-Hernández, Ana María Aquino-Zapata y Luis Hermann Bojórquez-Galván 29 (Holotipo, MEXU; Isotipo: CIB).
Planta subarbustiva a rastrera, de $60-90 \mathrm{~cm}$ de altura, terrestres y rupícolas (Figura 1A). Raíces fibrosas. Tronco ausente. Cladodios encadenados extendidos, ascendentes y decumbentes, obovados, anchamente obovados a subcirculares, brillantes, de $20 \times 16.5 \mathrm{~cm}$, verde-amarillentos, con podarios elevados (Figura 1B); epidermis papilosa; estomas ciclocíticos (Figura 2A). Aréolas dispuestas en 11-12 series, distantes $0.8-1.5 \mathrm{~cm}$ entre sí y $0.9-1 \mathrm{~cm}$ entre series, circulares, obovadas o elípticas, $c a .3 \mathrm{~mm}$ de largo o de diámetro, con fieltro marrón-negruzco (Figura 1B-C). Glóquidas amarillas, dispuestas en la parte superior de la aréola, como de $1 \mathrm{~mm}$ de largo (Figura 2B). Espinas con barbas retrorsas largas y elevadas, el ápice rojizo o marrón (Figura 2C), y la región media con 26 células paralelas entre sí, sin espacios intercelulares (Figura 2D); cerdas marrón-amarillentas, rojizas o marrón, el ápice amarillo, encorvadas desde la base, las radiales 2-8; en la parte inferior de la aréola, reflejas, de $1.5-2.6 \mathrm{~cm}$, cerdosas o setosas, onduladas, más numerosas en los bordes, de 0.4-0.9 cm de largo; las centrales 1-3, reflejas, de 3-4.1 cm de largo, más rígidas y más 

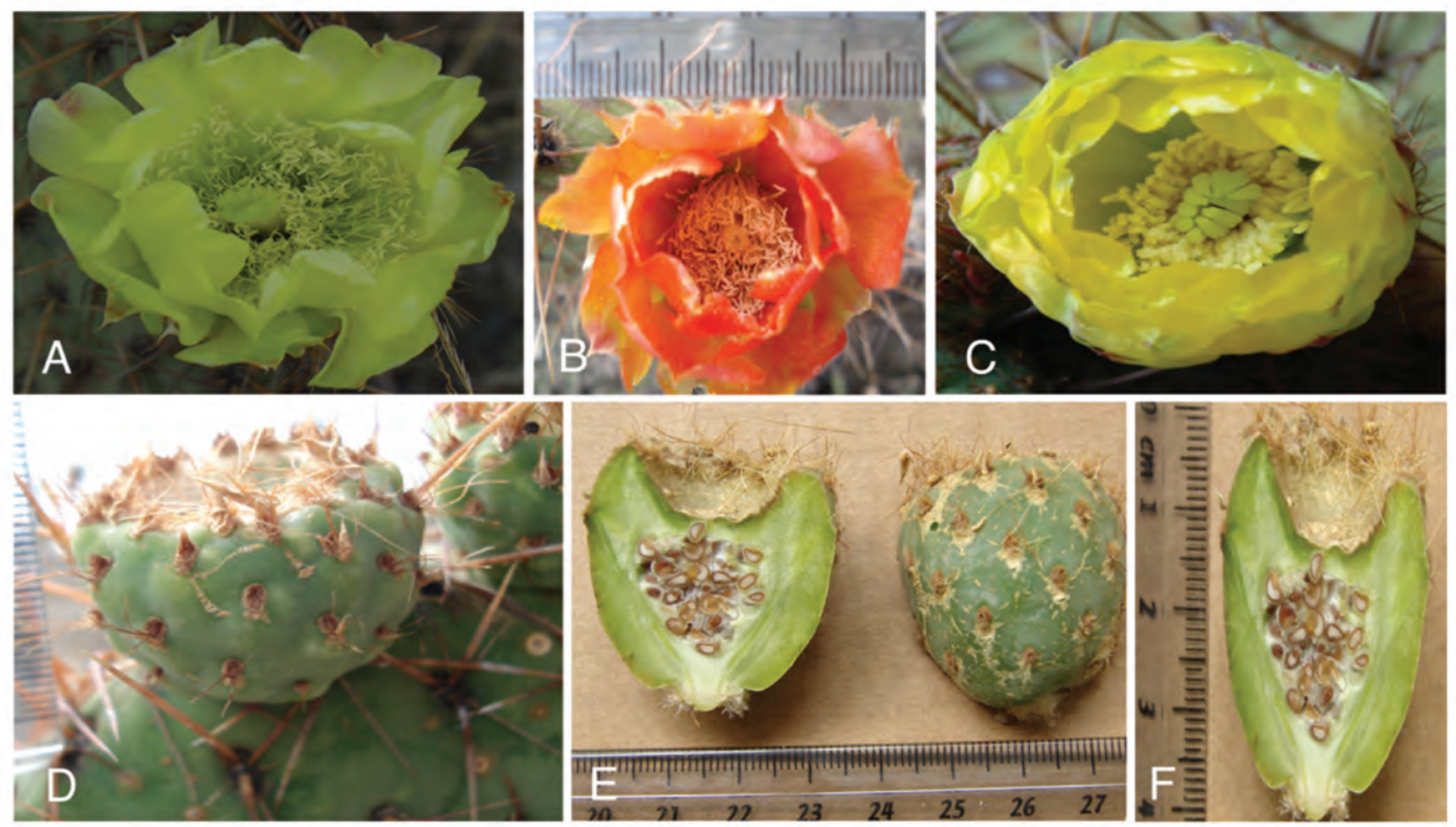

Figura 3. Opuntia perotensis sp. nov. A) Flor en antesis, $4 \mathrm{~cm}$ de diámetro, color amarillo-verdosa. B) Flor rosa-salmón, de $5 \mathrm{~cm}$ de diámetro. C) Flor amarilla, semi-cerrada, estambres blancos, lóbulos del estigma 12, en dos series paralelas, color verde claro. D) Fruto inmaduro, subgloboso, con cinco series de aréolas, con escama basal ascendente, rojiza, con algunas cerdas, cicatriz floral poco hundida. E) Fruto de color verde, corte longitudinal, vista interior y exterior, $3 \mathrm{~cm}$ de ancho, paredes de $1 \mathrm{~cm}$. F) Fruto inmaduro, obovado, $4 \mathrm{~cm}$ de largo, paredes anchas, semillas en el centro, con funículos secos. Fotos: Gustavo Moreno Hernández.

oscuras que las radiales; cerdas inferiores 1-5, onduladas, blanquecinas a grisáceas. Botón floral con pericarpelo con seis series de aréolas, con escamas basales blancas, ascendentes, lana marrón y cerdas apicales amarillas (Figura 1D). Flores diurnas, una en cada aréola, de 4-5 × 4.5-6 cm, pericarpelo subcircular, de $1.5 \mathrm{~cm}$ de diámetro, con aréolas elípticas, dispuestas en 6 series, con pelos blanco-rosados, hojas de las aréolas basales anchas, oblongas, con el ápice agudo y bordes ondulados; glóquidas en la parte superior de la aréola, amarillas; espinas radiales hasta 6 , ascendentes, hasta $0.4 \mathrm{~cm}$ de largo, rojas; espina central 1 , ascendente, hasta $1 \mathrm{~cm}$ de largo, roja con el ápice amarillo; segmentos exteriores del perianto espatulados, apiculados, margen ondulado, de 1.3-2 $\times 0.7-1.2 \mathrm{~cm}$, amarillo-verdosos, blanco-verdosos, amarillos o color rosa-amarillento (Figuras 1E-F); estambres numerosos, alcanzan la parte mediana de los segmentos interiores del perianto, amarillo pálidos, pasando al segundo día a color de rosa; estilo alcanza casi la misma altura de los estambres, de color amarillo-verdoso, lóbulos del estigma 10-12, en dos series paralelas entre sí, verdes o color rosa (Figuras 3A-C). Polen de dos tipos: uno con 12 poros y forámenes amplios (Fig. 4A-B) y, otro con 20 poros y forámenes muy cerrados (Figura 4C-D), Frutos amarillos, subglobosos a cilíndricos, de $4-5 \times 3.5 \mathrm{~cm}$, paredes exteriores con 5 series de aréolas elípticas, fieltro marrón, cerdas cortas, ascendentes, blancas y amarillentas, las superiores más largas, sin espinas, paredes interiores de $1.5 \mathrm{~cm}$ de ancho; cicatriz floral hundida, de aprox. $3 \mathrm{~cm}$ de diámetro, color rosa (Figuras 3D-F). Semillas aproximadamente 81 en cada fruto, dispuestas en el centro del fruto, reniformes, de $3 \mathrm{~mm}$ de diámetro, color crema, arilo seminal con tricomas largos, pluricelulares, agrupados en haces dispersos en toda la semilla; parte lateral del arilo angosto, irregular, región hilo-micropilar basal (Figuras 4E). La semilla de Opuntia huajuapensis es lenticular con algunos tricomas (Figuras 4F).

\section{Discusión}

A partir del análisis de la descripción original de Opuntia huajuapensis (Bravo-Hollis, 1954) y de las plantas colectadas y fotografiadas en el Cofre de Perote, se concluye que se trata de dos especies distintas, ubicadas en la Serie Criniferae (Bravo-Hollis, 1978, p. 315). Como característica sobresaliente de la nueva especie se observó que el arilo presenta tricomas largos; sus flores, el primer día son amarillas, el segundo día, al cambiar su pH, pasan a color salmón o rojo. Es probable que se trate de una especie de origen híbrido por presentar dos tipos de granos de polen. 

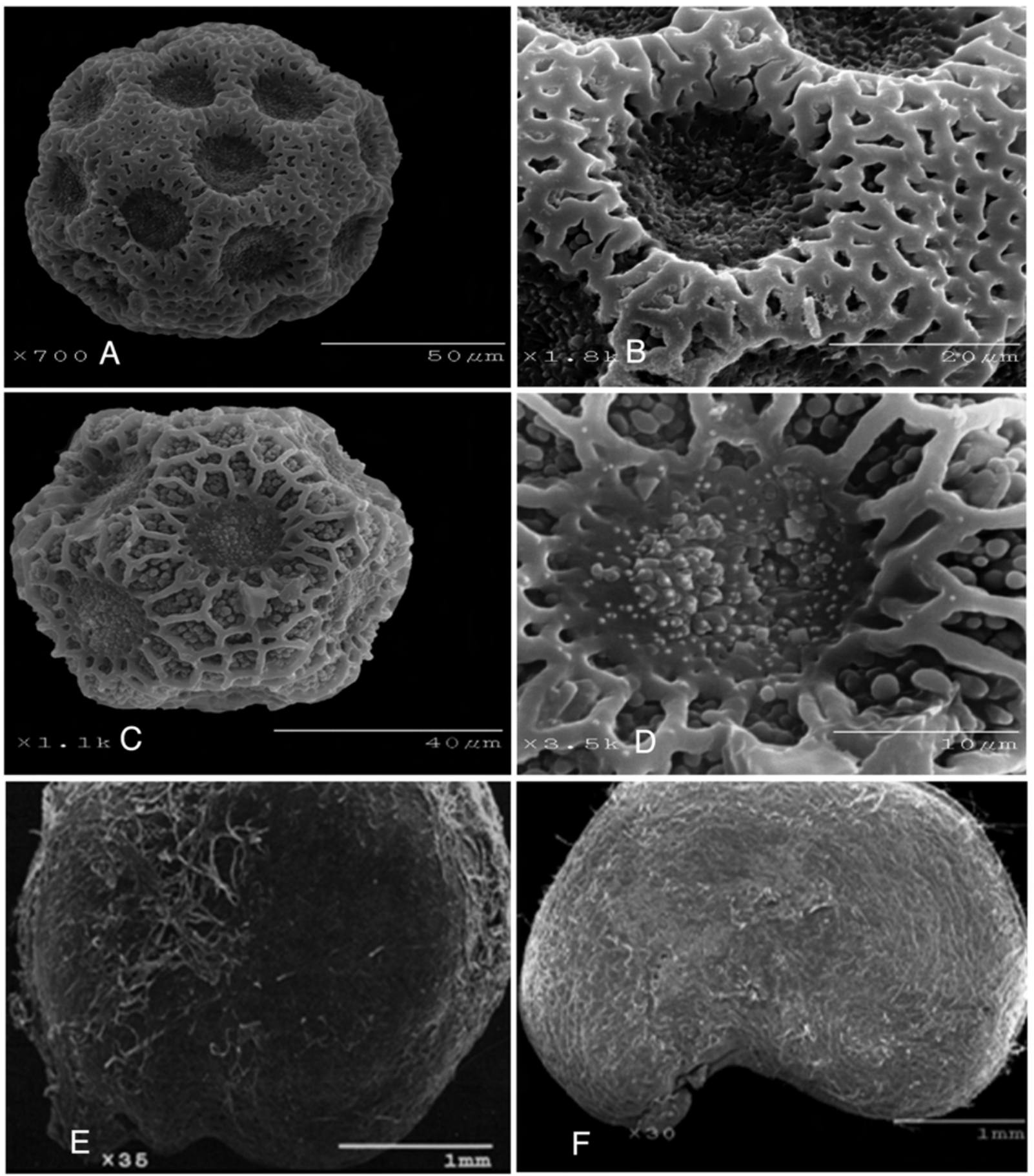

Figura 4. Opuntia perotensis sp. nov. A) grano de polen reticulado con fovéolos muy cerrados, B) retículo de la ectexina del grano de polen anterior, C) grano de polen reticulado con fovéolos muy abiertos y muros verrucosos, D) grano de polen con fovéolos muy abiertos. E) semilla reniforme, región hilo-micropilar basal, pubescente, recubierta de numerosos tricomas. F) semilla de Opuntia huajuapensis, lenticular con algunos tricomas.

Se elaboraron siete exiccata debidamente etiquetados, designando los tipos (un holotipo, un isotipo y cuatro topotipos; Cuadro 1). En uno de los camellones de la Colección Nacional ex situ de Nopales Silvestres Mexicanos, del Jardín Botánico del Instituto de Biología de la UNAM, se plantó un cladodio enviado por el biólogo Gustavo MorenoHernández (colecta número 4).

Distribución y ecología. Opuntia perotensis se conoce únicamente del Cofre de Perote, que es un área natural pro- 
LÉIA SCHEINVAR ET AL.

Cuadro 1. Características morfológicas distintivas de Opuntia huajuapensis y O. perotensis.

\begin{tabular}{|c|c|c|}
\hline Características & O. huajuapensis & O. perotensis \\
\hline Hábito & arbóreo y arbustivo & subarbustivo a rastrero \\
\hline Tronco & conspicuo, hasta $1 \mathrm{~m}$ de longitud cuando arbórea & ausente \\
\hline Cladodios forma & obovados a circulares & subcirculares, obovados a anchamente obovados \\
\hline Epidermis & pubescente, sin brillo, tricomas largos & pulverulenta, con brillo, papilas muy cortas \\
\hline Estomas & paracítico & ciclocítico \\
\hline Aréolas, series & 15-16(-19), distantes 2-3 cm entre sí & 11-12, distantes 0.8-1.5 cm entre sí \\
\hline Aréolas: color del fieltro & gris oscuro & marrón-negruzco \\
\hline Cerdas & rectas, blancas, $4-10$ & onduladas, amarillo-grisáceas y marrón, 1-5 \\
\hline Glóquidas vistas con MEB & con barbas pocas, adpresas, cortas & con barbas más numerosas, elevadas, largas \\
\hline $\begin{array}{l}\text { Región apical de las espinas } \\
\text { vistas con MEB }\end{array}$ & barbas cortas y adpresas & barbas largas y algo elevadas \\
\hline $\begin{array}{l}\text { Espinas (región mediana) } \\
\text { vistas con MEB }\end{array}$ & 44 cordones de células angostas y adpresas & 26 cordones de células paralelas entre sí, anchas \\
\hline Color de espinas & amarillo claras en la base y en el ápice más oscuras & rojizas o marrón \\
\hline Color de flores & amarillas, con ápices anaranjados & amarillas o rosas \\
\hline Pericarpelo & aréolas con numerosas espinas cerdosas hasta $3 \mathrm{~cm}$ & aréolas con escasas espinas cerdosas $<1 \mathrm{~cm}$ \\
\hline $\begin{array}{l}\text { Color del ápice de los } \\
\text { segmentos exteriores }\end{array}$ & rojos & verdes \\
\hline Filamentos & blancos a verde claros & amarillo pálidos pasando a color rosa \\
\hline Lóbulos del estigma, número y color & 5-9, de blancos a verde claro & $10-12$, rosa \\
\hline Granos de polen & $\begin{array}{l}\text { un solo tipo. Retículo muy abierto y angosto, } \\
\text { con } 12 \text { poros }\end{array}$ & $\begin{array}{l}\text { dos tipos. (1) Granos muy parecidos a } O . \\
\text { huajuapensis (poros } 12 \text { ); (2) Retículo muy } \\
\text { cerrado con más de } 20 \text { de los poros }\end{array}$ \\
\hline Frutos & $1-4.3 \mathrm{~cm}$ & hasta $5 \mathrm{~cm}$ \\
\hline Semillas & $\begin{array}{l}\text { elípticas a subglobosas, con tricomas en la } \\
\text { parte mediana }\end{array}$ & reniformes, recubierta de tricomas dispersos \\
\hline
\end{tabular}

tegida reducida del estado de Veracruz, con una altitud de 2,411 m s.n.m.; semiárido, con una precipitación media anual de $493.6 \mathrm{~mm}$ y heladas frecuentes; pequeñas lloviznas en invierno y primavera. Es la octava montaña más alta de México, se encuentra en la Faja Volcánica Transmexicana. La vegetación está compuesta por especies de Abies, Juniperus, Quercus y Pinus. El tipo de suelo que predomina es el regosol, altamente susceptible a la erosión, es también poroso, seco y semiárido.

Fenología: el período de floración es entre mayo y junio.

Etimología. El epíteto específico se refiere a la distribución geográfica conocida, endémica del Cofre de Perote, Veracruz, México.

Ejemplares adicionales examinados: México. Veracruz, Municipio Perote, Cofre de Perote, $1.5 \mathrm{~km}$ al SO del poblado Frijol Colorado, $19^{\circ} 34^{\prime} 44.5^{\prime \prime} \mathrm{N}, 97^{\circ} 21^{\prime} 52.3$ " O,
2,430 m s.n.m., Gustavo Moreno-Hernández 30, Ana María Aquino-Zapata y Luis Hermann Bojórquez-Galván (CHAP; IEB); Lat. N $19^{\circ} 34^{\prime} 43.2^{\prime \prime}$, Long. O 97 21' 54.1", Alt. 2,430 m s.n.m., Gustavo Moreno-Hernández 31, Ana Maria Aquino-Zapata y Luis Hermann Bojórquez-Galván (MEXU, ARIZ); $19^{\circ} 34.53$ ' 91" N, 97 21' 42.92"' O, 2,400 m s.n.m., Gustavo Moreno-Hernández 4 (MO).

\section{Agradecimientos}

Se agradece al Jefe del Jardín Botánico: Javier CaballeroNieto y al Director del Instituto de Biología de la UNAM: Víctor Manuel G. Sánchez Cordero-Dávila, por las facilidades otorgadas para la realización de la presente investigación. A los miembros del Instituto de Investigaciones Biológicas de la Universidad Veracruzana, Gustavo Moreno-Hernández, Ana María Aquino-Zapata y Luis Hermann Bojórquez-Galván, quienes enviaron las plantas colectadas en campo con sus fotos para su estudio. A Berenit Garfias 
y Dulce Ordóñez, quienes tomaron las microfotografías, al MEB del IB-UNAM y Marlenne Guadalupe Pineda, quien colaboró en el cultivo de plantas en la Colección Nacional ex situ de Nopales Silvestres Mexicanos del Jardín Botánico del IB-UNAM y en la organización del artículo.

\section{Literatura citada}

Bravo-Hollis H. 1954. Iconografía de las cactáceas mexicanas (tercera serie). Cactáceas de las Mixtecas Altas. Anales Instituto de Biología, Universidad Nacional Autónoma de México 25:473552.

Bravo-Hollis H. 1978. Las Cactáceas de México. Vol. 1. Universidad Nacional Autónoma de México, México, D.F.

Bravo-Hollis H. y Scheinvar L. 1995. El Interesante Mundo de las Cactáceas. Fondo de Cultura Económica, Consejo Nacional de Ciencia y Tecnología, México, D.F.

Felker P. 2001. Utilization of Opuntia for forage in the United States of America. En: Mondragón-Jacobo C. y Pérez-González S. Eds. Cactus (Opuntia spp.) as Forage, pp. 51-56, FAO Plant
Production and Protection Paper 169. Food and Agriculture Organization of the United Nations, Roma.

González D.A., Riojas L.M.E. y Arreola N.H.J. 2001. El género Opuntia en Jalisco: Guía de campo. Universidad de Guadalajara, Comisión Nacional para el Conocimiento y Uso de la Biodiversidad, Guadalajara.

Pinkava D.J. 2002. On the evolution of the continental North American Opuntioideae. En: Hunt D.R. y Taylor N.P. Eds. Studies in the Opuntioideae (Cactaceae). Succulent Plant Research. Vol. 6., pp. 59-98, Sherborne, Londres.

Pinkava D.J., Baker M.A., Parfitt B.D., Mohlenbrock M.W. y Worthington R.D. 1985. Chromosome numbers in some cacti of Western North America-V. Systematic Botany 10:471-483.

Scheinvar L., Olalde-Parra G y Gallegos-Vázquez C. (En prensa). Atlas de Nopales Silvestres Mexicanos. Instituto de Biología, Universidad Nacional Autónoma de México, Secretaría de Agricultura, Ganadería, Desarrollo Rural, Pesca y Alimentación, Sistema Nacional de Recursos Fitogenéticos para la Alimentación y la Agricultura, México, D.F.

Recibido: 14 de agosto de 2013

Aceptado: 23 de marzo de 2014 